DOI: https://doi.org/10.47405/mjssh.v5i6.433

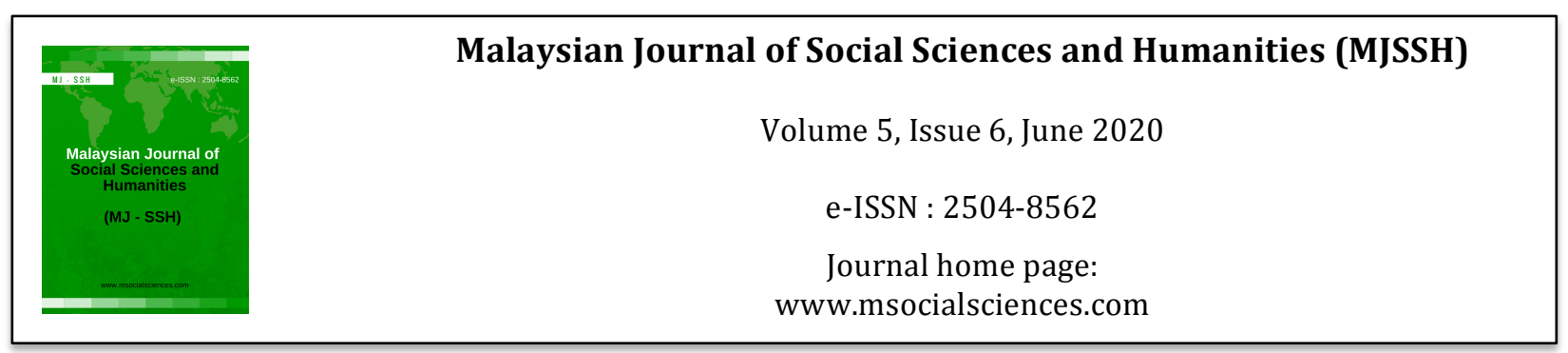

\title{
Improving Financial Performance Using Capital Budgeting Method Towards Cleaner Eyewear Product: A Case Study of Nasho
}

\author{
Mia Juliani', Raden Aswin Rahadi1 \\ ${ }^{1}$ School of Business and Management, Institut Teknologi Bandung, Indonesia \\ Correspondence: Mia Juliani (mia_juliani@sbm-itb.ac.id)
}

\begin{abstract}
The purpose of this study was to know the factor that can be improved in the financial performance of Nasho. Nasho is a brand that focuses on offering products for eyeglass and helmet application that can be water, dew and dust repellent by utilizing the application of nanotechnology in the scope market of Bandung. However, to adapt the technology for Nasho is currently hampered by the limited capital to develop the technology itself. The company needs to manage the capital and minimize the cost to optimize the finance. The company needs to control the cost and expenses to avoid the high number of costs and expenses in terms of the development business stage. The research will use a qualitative approach by conducting interviews to Mr. Reza optics that will cooperate with Nasho to sell the product and use secondary data information from literature review, journal, books and primary data from financial history of Nasho and survey from the consumer of Nasho namely College student, Medical staff and Motorcycle riders and the components that are relevant to the conceptual framework. Survey used to get the consumer product and buying tendency information from Nasho's consumer to validate the assumption of brand, price and buying intencity. Interview was conducted to get the suitable number of sales that are being used for cash flow forecasting scenario. The findings of this research is Nasho had low financial performance in the first two years of the business. After the evaluation, this can be improved by making a financial planning mix for short term and long term using the capital budgeting method in the form of three optimal scenarios of cash flow, Net Present Value (NPV), IRR and payback period that can be used as an optimal plan to run this business for the next five years.
\end{abstract}

Keywords: nanotechnology, eyewear product, financial performance, financial planning, capital budgeting

\section{Introduction}

Nanotechnology study and application rising rapidly (Duncan, 2011). Nano coating is among the applications of nanotechnology. According to the literature, smart coatings can be applied to anticorrosion, anti-wearing, anti-fungal, self-cleaning, super-hydrophobic, solar-reflective, photo-catalytic and radar absorbing and electrically conducting polymer applications (Phuong et al., 2019). Nano coating can be used on a number of items, including helmet visor and glasses (Phuong et al., 2019). Indonesia's market potential for eyewear products. At least 80 million Indonesians are considered worthy of the survey and must use glasses (The Ministry of Industry, 2018). 
Nasho focuses on providing a device for the application of eyeglass and helmet, as a solution for clear vision in everyday use, the product to helmet and eyeglass nano coating liquid, which provides water repellent, anti-fog, anti-dust and antibacterial features. Nasho sees that a more important issue can be solved with the use of nanotechnology coating. The numbers of road injuries are rising year by year. In Indonesia, 69 percent or 4000 cases of incidents were caused by the rain from natural causes.

Nasho spread safety consciousness by encouraging a clear vision for consumers of eyeglasses and helmets while riding and performing everyday activities. "Nasho" means Nanotechnology for Solution, meaning this company intended to be Indonesia's market leader in liquid nanotechnology coating for glass and lens treatment.

\section{Problem Statements}

Nasho as a Small Medium Enterprise (SME) company has limited resources. Nasho can not handle the capital well so the company would not be able to maximize the finances and operate well, too proven from the company's outflow results, Nasho found there are several "ERROR" estimates in the outflow record.

In 2018 until 2019, Nasho had a high number of costs and expenses. Nasho did not know how much money was needed to free up goods. And now the company has no balance between outflow and financial records inflow. Nasho requires good financial reporting and expense minimisation. Nasho needs to boost the financial results to maximize the finances for the company.

\section{Objectives}

i. To analyse the current business condition and financial history

ii. To find out the factors that can be improve to optimize the financial performance of Nasho

iii. To get the optimal scenario for Nasho based on the consumer preferences

iv. To know the most feasible financial planning should Nasho make to keep the company sustained

\section{Literature Review}

\section{Financial Performance}

Financial Performance has a causal relationship (Sohn et.al, 2005) with a company's evaluation factors such as profitability, growth, liquidity, debt, turnover and valuation ratios. Measurement of financial performance is useful for evaluating the effectiveness of a critically planned plan in the literature strategy that will be the focus of the future (Weston \& Thomas, 1985).

\section{Financial Planning}

Financial planning is one of the tools that can be used to estimate the short-term and long-term financial needs of a company (Gitman \& Zutter, 2014). Financial planning is interesting because there are risks in every investment and financial market (Mahapatra et al., 2019).

\section{Financial Statement}

In evaluating financial performance, the company's financial statements are the usual starting point. To make an effective decision both in terms of investing or landing, we need complete information about company finances. Financial statement is one of the tools that contains the information, then the information will be considered in decision making (Gibson, 1992). 
Financial summaries of the results of operations of the company during a certain period will be presented in the form of income statements. Generally, this income statement includes a report for 1 year of the company's operational period (Gitman \& Zutter, 2014).

A balance sheet presents a statement of balance between a company's assets and financing can be in the form of debt or equity. So, in general, the balance sheet is a summary report about the financial position of a company within a certain period (Gitman \& Zutter, 2014). The availability of cash flow greatly affects the relationship between work capital management and company performance so it can be said that the availability of cash flow will affect the amount of investment in a company for working capital (Hill et al., 2010).

\section{Capital Budgeting}

One of the factors of a company's success is the right investment decision and to get that decision a company needs to make the right capital budgeting (Britzel et al., 2020). Capital budgeting is the planning process used to determine whether long-term investments in assets will be tangible (Vecchi \& Casalini, 2018).

The payback period gives the estimated period needed by a company to cover investment costs using existing cash flow. It can be said that the payback period is the ratio between the income statement and the initial ratio which can later produce a unit of time in its calculation (Husein, 2000).

To determine whether a business is attractive enough to be invested or not, we can measure it using Net Present Value (NPV). If after the negative NPV results are calculated, it shows that the business is not profitable enough and vice versa if the NPV results are positive then the business will be profitable if invested (Bradford, Randolph \& Stephen, 2010).

Table 1: The Role of NPV

\begin{tabular}{lll}
\hline If & Then & Means \\
\hline NPV $<0$ & IRR $<$ Cost Of Capital & Not Accepted Project \\
NPV $=0$ & IRR $=$ Cost Of Capital & Not Accepted Project \\
NPV $>0$ & IRR $>$ Cost Of Capital & Accepted Project \\
\hline
\end{tabular}

IRR provides estimates that summarize the benefits of a business project in the company and become one of the references in calculating the efficiency of an investment. IRR calculation can be the basis of whether an investment is feasible or not. Interest rates on the capital market do not affect the amount (Ross, Westerfield, \& Jaffe, 2010). IRR has a relationship with NPV.

Cash flow forecasting is needed for access to the expansion phase by calculating increasing capital for SMEs (Fight, 2005). To obtain capital loans an important part needed is that businesses can show their periodic cash flow estimates (Navon, 1995).

\section{Conceptual Framework}

From Nasho's historical financial data it was found that there was a high number of costs and expenses in 2018 to 2019. Financial performance evaluation uses financial statements consisting of income statements, balance sheets and statements of cash flow (Knight \& Bertoneche, 2000). Improving financial performance can use the capital budgeting method by calculating forecasting scenarios for NPV, IRR and payback periods (McKiernan \& Morris, 1994). 


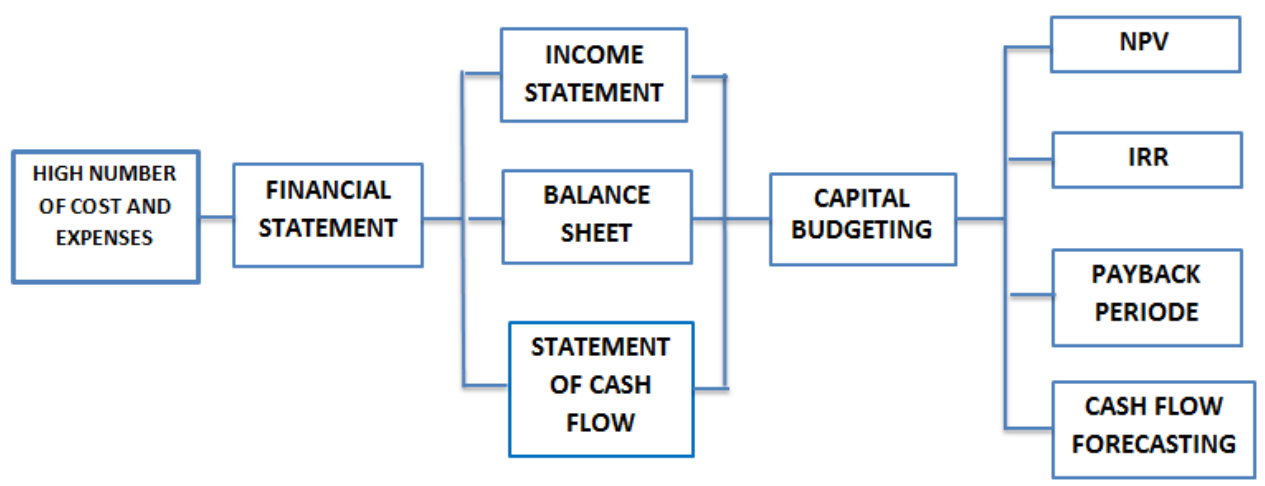

Figure 1: Conceptual Framework

\section{Methodology}

The main data are obtained from interviews with one optics in Bandung. The interview was conducted via Whatsapp free call for two hours with the speaker being the optical owner. This optic was chosen because it is an optic that will cooperate with Nasho to sell its products. This optics is in the medium category, which has a permanent shop, the owner has experienced in this field for around 17 years and the shop has been operating for more than 6 years.

The purpose of this interview is to obtain forecasting figures from the sale of optic cleaning products in the optics. This interview is divided into three sections. The first section is the question about personal information from the optical owner, the second is about the optical establishment information, which is about eyewear brand products sold at the optics and the last is related to the sales figures of the optics. From these sales figures, the researcher will get the suitable number of sales to be applied to the Nasho capital budgeting calculation.

The researcher also conducted a survey to find out Consumer Product And Buying Tendency. The survey was filled by 53 respondents who were the target market of Nasho, namely medical staff, college students and motorcyclists who used glasses. The results of this survey will help validate the range of cleaning product prices and buying tendency of cleaner eyewear products.

This survey consists of 14 questions including personal data, e-mail address, name, age and occupation, the second question relates to what problems are commonly encountered when using glasses and the last question is about eyeglass cleaning products used including brand, product price and purchase intensity within one month

\section{Analysis And Results}

\section{Financial Statement Analysis}

Financial statement analysis is taken from Nasho's financial historical data from 2018 to 2019. The results of the table above shows that Nasho's financial performance has decreased marked by the results of the calculation of income statements and statement of cash flow has decreased in the second year minus IDR10,565,690 to -IDR6,418,100 for income statement and IDR10,565,690 to IDR 5,488,100 for statement of cash flow.

Table 2. Financial Statement of Nasho

\begin{tabular}{lcc}
\hline & $\mathbf{2 0 1 8}$ & $\mathbf{2 0 1 9}$ \\
\hline Income Statement & IDR10,565,690 & -IDR6,418,100
\end{tabular}


DOI: https://doi.org/10.47405/mjssh.v5i6.433

\begin{tabular}{lll}
\hline Balance Sheet & IDR13,176,000 & IDR15,869,000 \\
Statement Of Cash Flow & IDR10,565,690 & -IDR5,488,100 \\
\hline
\end{tabular}

\section{Consumer Product And Buying Tendency}

The researcher conducted a survey of 53 respondents who were eyeglasses users with a ratio of $88 \%$ of students aged $17-21$ years, about $10 \%$ of others aged $22-26$ years and $2 \%$ of medical staff. This survey was conducted to obtain initial assumptions from the perspective of consumers about eyeglass cleaning products used by consumers as well as the intensity of purchasing these products within a span of one month, in addition to that, also obtained data on the prices of eyeglass cleaning products commonly purchased by consumers.

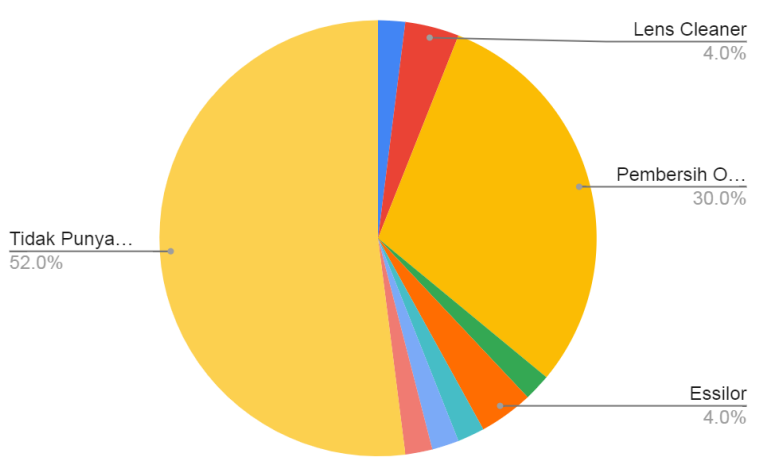

Figure 2: Brand Of Variance

The picture above shows that prospective Nasho consumers use various brands as their eyeglass cleaning products, but more customers do not have eyeglass cleaning products because as many as $52 \%$ say they do not have eyeglass cleaning products, then $30 \%$ use eyeglass cleaner without brand and the brands with the most users are Lens Cleaner and Essilor with the same percentage of $4 \%$.

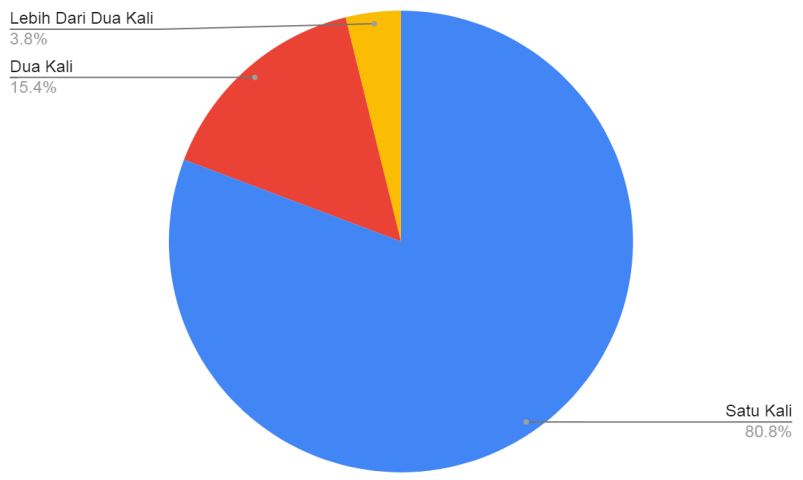

Figure 3: Buying Tendency

The data shows the intensity of the purchase of eyeglass cleaning products in a span of one month. $80.8 \%$ bought eyewear products once a month, $15.4 \%$ twice a month and another $3.8 \%$ more than twice a month.

Table 3: Price Variance

\begin{tabular}{cccccccc}
\hline IDR3,000 & IDR10,000 & IDR15,000 & IDR20,000 & IDR50,000 & IDR55,000 & IDR80,000 & IDR150,000 \\
\hline $4 \%$ & $20 \%$ & $20 \%$ & $20 \%$ & $20 \%$ & $8 \%$ & $4 \%$ & $4 \%$ \\
\hline
\end{tabular}

Based on the table above, most consumers buy eyeglass cleaning products at a range price of IDR 10,000 until 50,000 with a same data percentage of $20 \%$. While with the same percentage of $4 \%$, 
consumers choose products with prices of IDR 3,000, IDR 80,000 and IDR 150,000. And 8\% for IDR 80,000 .

\section{Thematic Analysis}

Thematic analysis is one way to analyze data to identify patterns through data that has been collected by researchers consisting of five stages namely interview transcript, incidents, tentative codes, codes and dimension (Braun \& Clarke, 2006). Thematic analysis is an effective method to find out in detail qualitative data to find the interrelation of patterns in a phenomenon and explain how the phenomenon occurs through the view of researchers (Fereday \& Muir-Cochrane, 2006).

\section{Dimension}

This dimension illustrates the important things that are in the data related to research problems (Boyatzi, 1998) more clearly says that this dimension illustrates the pattern of the phenomenon under study.

Table 4: Dimension Analysis

\begin{tabular}{c}
\hline Dimension \\
\hline Business Background \\
Main Product \\
Opportunity \\
Complementary Product \\
Sales Record \\
\hline
\end{tabular}

The dimension of the business background shows that the owner of Oprik, Mr. Reza, is very experienced in the field of optics because he has worked for 17 years, from large optics to owning their own optics. Optics Pak Reza is indeed not large but can be categorized as a medium optics because the optics already have a permanent store and have been in operation for more than 6 years.

Eyewear products sold in optics are in the form of frames, lenses, eyeglasses storage, rags and cleaning fluid. This product is obtained from suppliers with various prices depending on the type. However, Pak Reza guarantees that the eyewear products in his optics are of good quality.

Opportunity to build an optical business is big, Mr. Reza said that based on his experience, the need for optics continues to increase because the number of glasses users is also increasing, $70 \%$ of customers are young people from elementary school to junior high school students. One of the factors that influence this increase is also the awareness of eye health.

Main products that are sold in Mr. Reza's optics are glasses but Mr. Reza also sells a variety of complementary products such as eyeglass cleaners. Pak Reza bought them wholesale at $30 \mathrm{ml}$ bottle sizes and the number of purchases per dozen. Pak Reza sells these cleaners with his glasses or sold separately. The usual brand that Pak Reza sells is the cleanser from Essilor and the Lens Cleanser brand. The price range is IDR 10,000 to 25,000 .

Sales record from Pak Reza's optics in a month is exactly 10 dozen eyeglasses storage, 100 pieces of eyeglass frames, 10 dozen eyeglasses, 12 dozen cleaning fluids for relatively stable sales, but if in large optics the number of sales can double. 


\section{Cash Flow Forecasting}

Sales Revenue is derived from sales data and purchase price ranges from consumers and eyewear stores on average every month which are then converted to units of the year by researchers.

Table 5: Cash Flow Forecasting Scenario

\begin{tabular}{cccc}
\hline Year & Best Scenario & Normal Scenario & Worst Scenario \\
\hline $\mathbf{1}$ & IDR1,848,300,000 & IDR445,400,000 & IDR97,500,000 \\
$\mathbf{2}$ & IDR5,753,100,000 & IDR1,731,900,000 & IDR405,200,000 \\
$\mathbf{3}$ & IDR13,094,400,000 & IDR4,557,800,000 & IDR $1,280,200,000$ \\
$\mathbf{4}$ & IDR30,252,000,000 & IDR11,155,400,000 & IDR3,587,800,000 \\
$\mathbf{5}$ & IDR68,529,600,000 & IDR26,333,000,000 & IDR10,515,400,000 \\
\hline
\end{tabular}

This research will produce three cash flow forecasting scenarios, namely best, normal and worst, which are shown in the table above. The table shows three cash flow forecasting scenarios for five years starting from year 1 to 5 .

\section{NPV, IRR And Payback Period}

Table 5 shows the NPV, IRR and Payback Period projection for the next five years that consist of three scenarios namely best scenario, normal and worst scenario.

The results of the NPV are acceptable because positive or $>0$ means that this business is a good project to invest. The IRR results in the table are acceptable because they are bigger than the WACC which is $11.28 \%$. The weighted average cost of capital (WACC) is the result of the calculation of the risk free rate, market return and beta of the eyewear industry. The cost of capital is calculated using the CAPM (Capital Asset Pricing Model) method. With the formula below

$$
\begin{gathered}
R a=R r f+[\beta a \times(R m-R r f) \\
E R i=7.91 \%+0.74(12.46 \%-7.91 \%)=11.28 \%
\end{gathered}
$$

Where :

$R a=$ Cost of Equity

$\operatorname{Rrf}=$ Risk Free Rate

$B a=$ Beta Of Industry

$R m=$ Market Rate Of Return

Table 6: NPV, IRR, Payback Period

\begin{tabular}{cccc}
\hline & Best Scenario & Normal Scenario & Worst Scenario \\
\hline NPV & IDR98,472,837,871 & IDR36,302,846,580 & IDR12,904,432,747 \\
IRR & $642 \%$ & $421 \%$ & $256 \%$ \\
$\begin{array}{c}\text { Payback } \\
\text { Period }\end{array}$ & 2 Months & 3 Months & 4 Months \\
\hline
\end{tabular}




\section{Conclusion And Recommendation}

After analyzing the internal financial history of Nasho using financial statement calculations covering income statements, balance sheets and statement of cash flow shows there was a decrease in financial performance in the first two years. The reason is that Nasho did not have financial planning in managing his finances. Survey results for Nasho consumers show that consumers buy cleaning products approximately once a month with a price range of IDR 10,000 to IDR 50,000 . This is reinforced by the results of interviews with the optics Mr. Reza said that usually people will buy cleaning once a month with a price range of IDR 10,000 to IDR 25,000.

To improve the financial performance of Nasho, the company can mix for short and long-term financial planning using capital budgeting methods covering NPV, IRR, Payback period and cash flow forecasting scenario which can be seen in tables 4 and 5 to optimize the finance. At the beginning of its development, Nasho will take advantage of the initial investment obtained from funding and the remaining capital in the previous year. Modification of general expenses is needed to make this scenario effective and generate appropriate cash in flow.

\section{References}

Boyatzis, R.E. (1998). Transforming qualitative information: Thematic analysis and code development. Thousand Oaks: Sage.

Bradford D. Jordan, Randolph W. Westerfield, Stephen A. Ross. (2010). Fundamental of Corporate Finance . New York: McGraw Hill.

Braun, V., \& Clarke, V. (2006). Using thematic analysis in psychology. Qualitative Research in Psychology,3(2), 77-101.

Britzelmaier, B., Pöpplow, U., \& Andraschko, L. (2020). Capital budgeting practices of SME in Baden-Württemberg: findings of an empirical study. International Journal of Business and Globalisation, 24(1), 78-93.

Duncan, T. V. (2011). Applications of nanotechnology in food packaging and food safety: barrier materials, antimicrobials and sensors. Journal of colloid and interface science, 363(1), 1-24.

Fereday, J., \& Muir-Cochrane, E. (2006). Demonstrating rigor using thematic analysis: A hybrid approach of inductive and deductive coding and theme development. International Journal of Qualitative Methods, 5(1), 80-92.

Gibson, B. (1992). Financial information for decision making: An alternative small firm perspective. The Journal of Entrepreneurial Finance, 1(3), 221-232.

Gitman, L. J., \& Zutter, C. J. (2012). Principle of Managerial Finance (13th ed.). Essex, England, United Kingdom: Pearson.

Hill, M. D., Kelly, G. W., \& Highfield, M. J. (2010). Net operating working capital behavior: a first look. Financial management, 39(2), 783-805.

Knight, R., \& Bertoneche, M. (2000). Financial performance. Elsevier.

Mahapatra, M. S., Raveendran, J., \& De, A. (2019). Building a Model on Influence of Behavioural and Cognitive Factors on Personal Financial Planning: A Study Among Indian Households. Global Business Review, 20(4), 996-1009.

McKiernan, P., \& Morris, C. (1994). Strategic planning and financial performance in UK SMEs: does formality matter?. British Journal of Management, 5, S31-S41.

Phuong, D. T. V., Sancharoen, P., Klomjit, P., \& Tangtermsirikul, S. (2019, October). Effects of w/b ratio, fly ash, and chloride content on corrosion of reinforcing steel. In IOP Conference Series: Materials Science and Engineering (Vol. 615, No. 1, p. 012005). IOP Publishing.

Sohn, S. Y., Moon, T. H., \& Kim, S. (2005). Improved technology scoring model for credit guarantee fund. Expert Systems with Applications, 28(2), 327-331.

Vecchi, V., \& Casalini, F. (2018). Principles of Capital Budgeting for the Assessment of PPP Projects. In Public-Private Partnerships in Health (pp. 65-84). Palgrave Macmillan, Cham.

Weston, J. F., \& Copeland, T. E. (1995). Manajemen keuangan, edisi kesembilan. 